Erratum

\title{
Erratum to "Radial Quantitative Ultrasound and Dual Energy X-Ray Absorptiometry: Intermethod Agreement for Bone Status Assessment in Children"
}

\author{
Kar Hau Chong, ${ }^{1}$ Bee Koon Poh, ${ }^{1}$ Nor Aini Jamil, ${ }^{1}$ \\ Nor Azmi Kamaruddin, ${ }^{2}$ and Paul Deurenberg ${ }^{3}$ \\ ${ }^{1}$ Physical Activity and Energy Metabolism Research Group, Faculty of Health Sciences, \\ Universiti Kebangsaan Malaysia, Jalan Raja Muda Abdul Aziz, 50300 Kuala Lumpur, Malaysia \\ ${ }^{2}$ Department of Medicine, Faculty of Medicine, Universiti Kebangsaan Malaysia, Jalan Yaacob Latif, \\ Bandar Tun Razak, 56000 Cheras, Kuala Lumpur, Malaysia \\ ${ }^{3}$ Telaga Harbour Marina, Lot 1, 07000 Langkawi, Malaysia
}

Correspondence should be addressed to Bee Koon Poh; pbkoon@ukm.edu.my

Received 27 May 2015; Accepted 2 June 2015

Copyright (C) 2015 Kar Hau Chong et al. This is an open access article distributed under the Creative Commons Attribution License, which permits unrestricted use, distribution, and reproduction in any medium, provided the original work is properly cited.

In our paper entitled "Radial Quantitative Ultrasound and Dual Energy X-Ray Absorptiometry: Intermethod Agreement for Bone Status Assessment in Children," there was an error in the title of $x$-axis in Figure 1 . The title was written as "Difference in $Z$-score (radial QUS minus DXA)"; however, it should be written as "Mean of $Z$-scores of radial QUS and DXA." We have now provided new corrected Figure 1.

These corrections do not change any conclusion or findings of the paper.

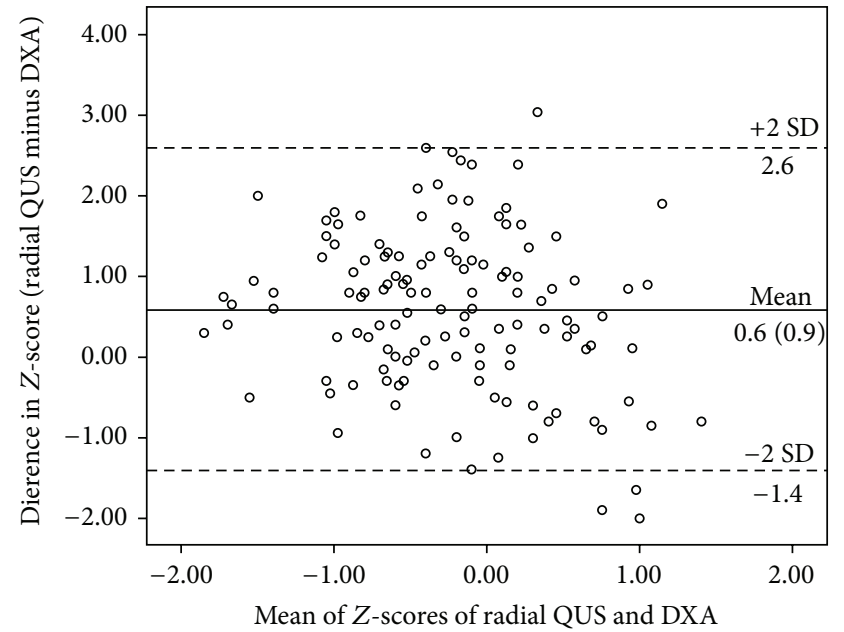

FIGURE 1: Bland-Altman plot for assessing the agreement between radial quantitative ultrasound (QUS) and dual energy X-ray absorptiometry (DXA). 


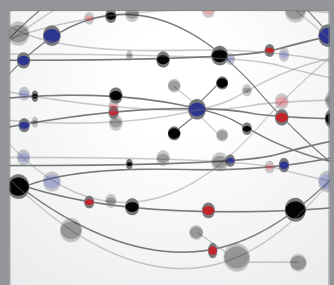

The Scientific World Journal
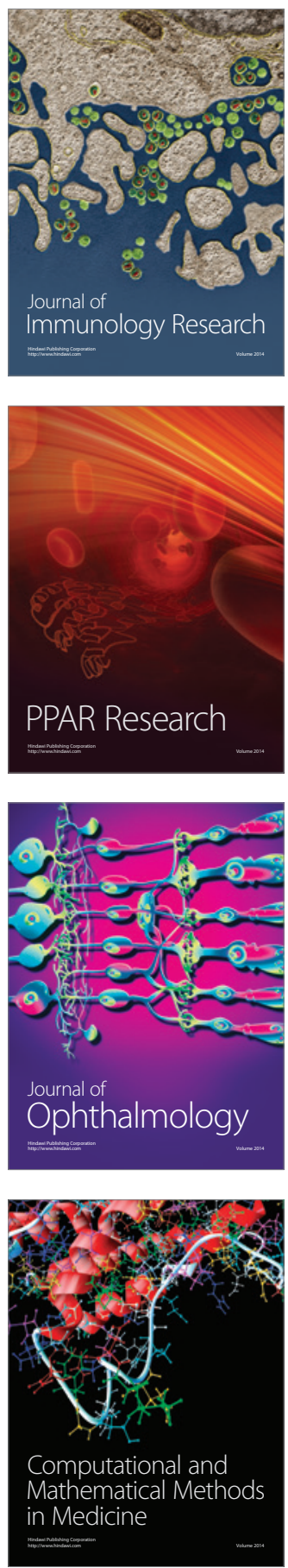

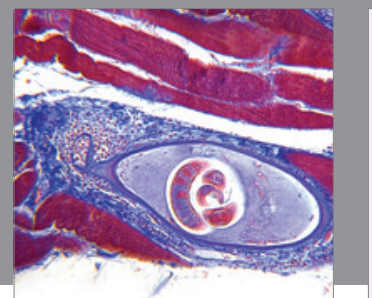

Gastroenterology

Research and Practice
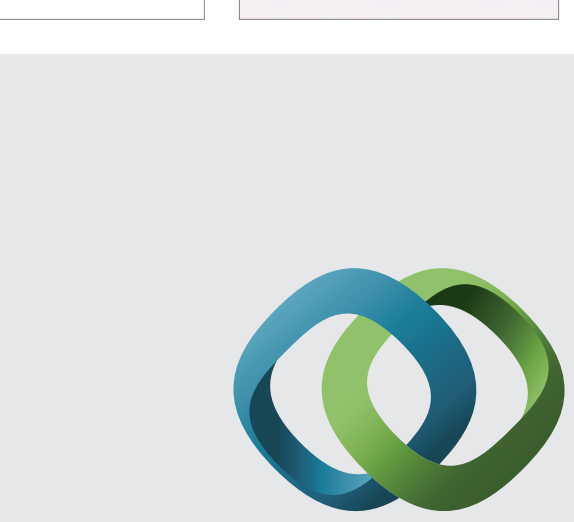

\section{Hindawi}

Submit your manuscripts at

http://www.hindawi.com
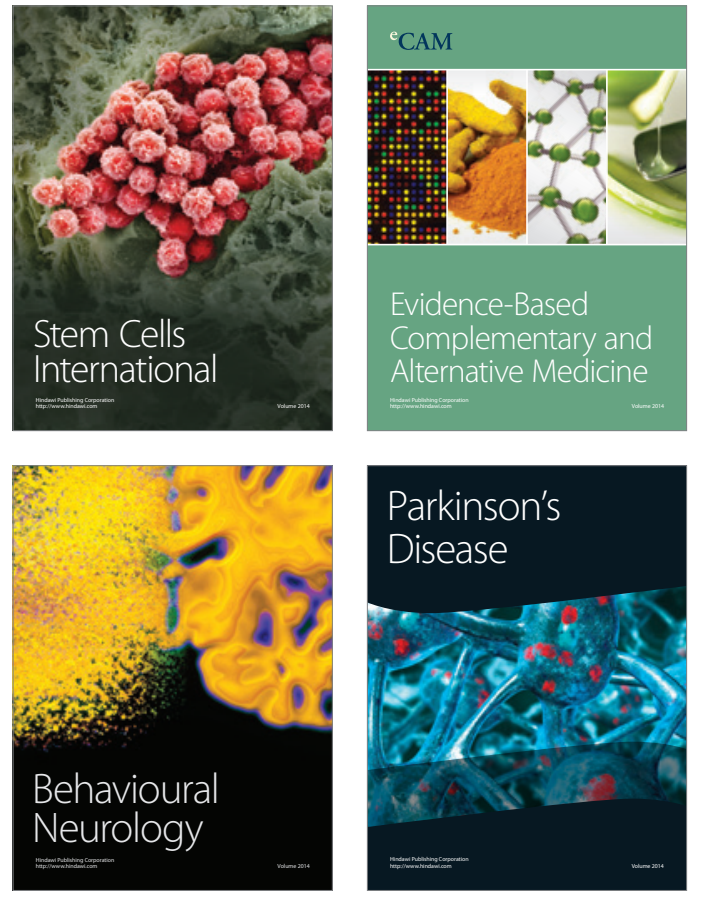
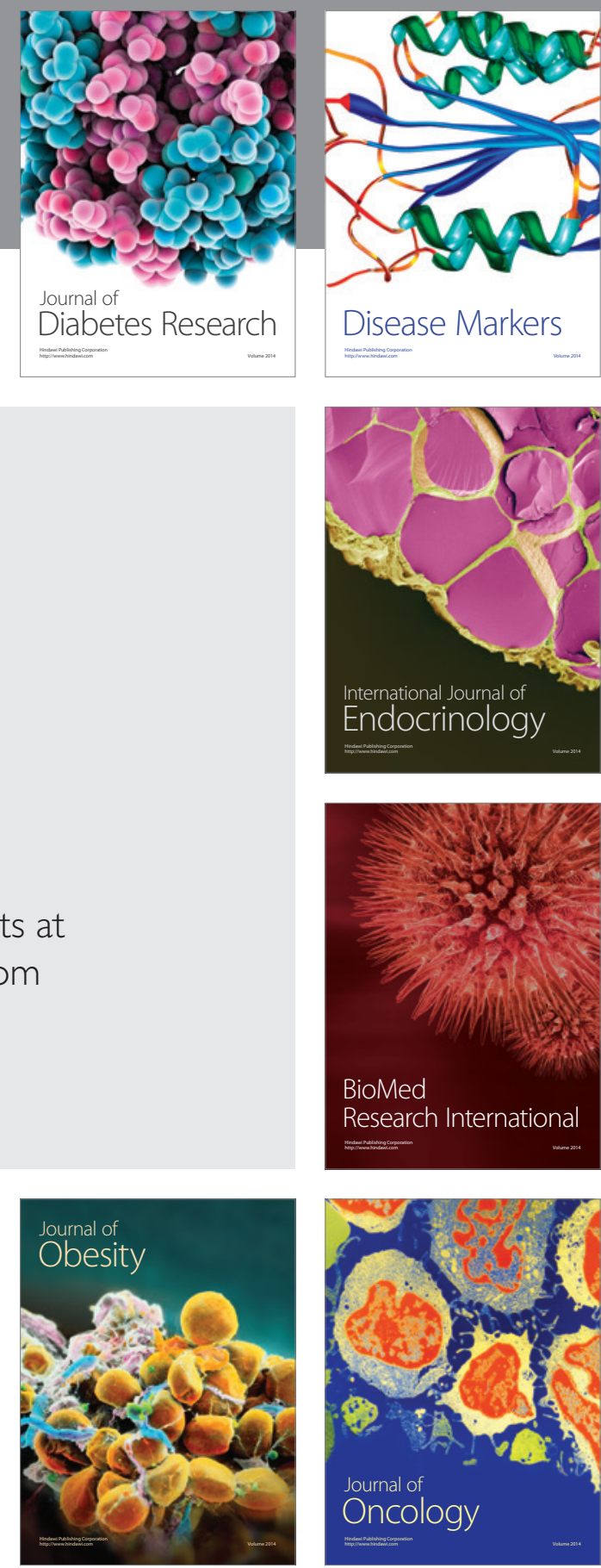

Disease Markers
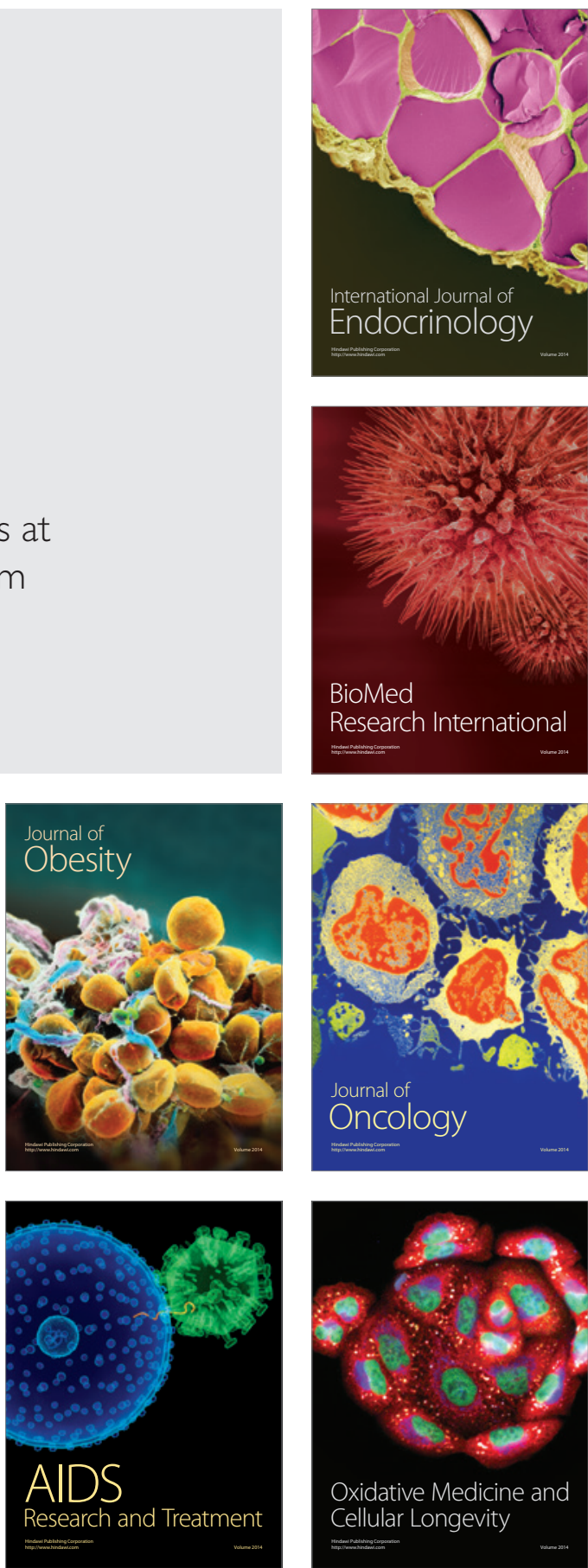